\title{
OS ESTÁGIOS E AS PRÁTICAS NA FORMAÇÃO DE GRADUANDOS/AS NA ÁREA DE LÍNGUAS DA UEPG
}

Ligia Paula COUTO

Universidade Estadual de Ponta Grossa

\begin{abstract}
RESUMO: Nesta comunicação, trataremos das disciplinas de estágio e prática na formação de graduandos/as em Letras da UEPG. No período de 2012 a 2014, os cursos de Letras (Espanhol, Francês e Inglês, todos com dupla habilitação em Português) passaram por reestruturação curricular, sendo que 2015 foi o primeiro ano de implantação do novo currículo. Nesta proposta, consideráveis mudanças foram implementadas para as disciplinas de Estágios e Práticas. Assim, nossa metodologia, para este estudo, se pauta na análise documental do projeto pedagógico do curso (PPC) no que se refere à proposta para os estágios e as práticas, focando os processos de implantação da nova proposta nos referidos cursos. Como resultados, esperamos confrontar o PPC escrito com o vivido de forma a evidenciar os caminhos já percorridos nesta implantação curricular de forma a contemplar a proposta e as estratégias que ainda precisam ser desenvolvidas para que o currículo se efetive de forma mais coerente e efetiva. Estágios e práticas são disciplinas fundamentais na formação docente de graduandos/as dos cursos de Letras, assim, estas disciplinas necessitam dialogar e se complementar almejando contribuir com a construção de conhecimentos pedagógicos e vivências pedagógicas significativos para uma profissionalização docente de qualidade.
\end{abstract}

PALAVRAS-CHAVE: Estágios; Práticas; Cursos de Letras

ABSTRACT: This article focuses on the Teaching Practicum and Practical components of the curriculum of the undergraduate Letras courses at the State University of Ponta Grossa (UEPG, in the Portuguese acronym). From 2012 to 2014, the undergraduate Letras course (Spanish, French and English, all of which offer a Portuguese degree in addition to the foreign languages) underwent curricular restructuring. The new curriculum was implemented in 2015 for the first time. In this new curricular proposal, significant changes affected the Teaching Practicum and Practical components. The methodology for this study is based on the analysis of the pedagogical project of the course (PPC) concerning the proposal for the teaching practicum and practical components of the course, focusing on the implementation process of the new proposal to the aforementioned courses. The outcomes of the study include the comparison of the written PPC with what really takes place when it is implemented in order to show what has already taken place and consider the proposal and strategies that still need to be developed so that the curriculum is implemented in a more coherent and effective way. The Teaching Practicum and Practical component are essential to the initial education of the undergraduate students of the Letras courses. Thus, these disciplines should be in line and complement one another aiming to contribute to the construction of pedagogical knowledge and meaningful pedagogical experiences for quality teacher's professionalization. KEYWORDS: Teaching Practicum; Practice; Language Course.

\section{Introdução}

Este trabalho se inseriu no Simpósio "Novas Proposições Curriculares para a Formação de Professores de Línguas", na temática Currículos de Formação Docente. Tal Simpósio se propôs a debater novas proposições curriculares para a formação pedagógica de professores de línguas no contexto de duas universidades paranaenses: a UEPG, com atividades iniciadas em 1969, e a UNILA, com atividades iniciadas em 2010. Todas as participantes deste Simpósio que representam a UEPG são membros do Núcleo Docente Estruturante dos Cursos de Letras (NDE Letras); neste sentido, os três trabalhos apresentados dialogam para destacar as ações do NDE em efetivar o projeto político pedagógico do curso 
(PPC). No caso específico, vou aprofundar a atuação do NDE Letras para a implementação de uma nova proposta para as Práticas Articuladoras e os Estágios e a aproximação entre essas duas disciplinas.

É importante destacar que os cursos de Letras existem há mais de 80 anos na estrutura das universidades brasileiras, assim, passaram por muitas avaliações e reestruturações, sendo que o currículo, inserido no PPC, se torna um documento que registra esse processo de mudança.

Estudos na área do currículo permitiram compreender a importância do PPC na organização do conhecimento para a constituição da estrutura escolar em diferentes níveis. De acordo com Moreira e Silva (1994), o currículo passou a ser uma área de investigação e análise de teóricos da educação e considerado peça chave no entendimento da dinâmica escolar. Com a intensificação dos estudos nesta área, analisar o currículo passou a problematizar questões de poder, ideologia e cultura. A vinculação de currículo a tais questões está relacionada diretamente à seleção dos conteúdos que o rechearão. Além disso, Alves (2002, p. 40-41) explica que o currículo somente pode ser compreendido a partir do "saber dos sujeitos praticantes do currículo", isto é, o currículo se manifesta nas relações estabelecidas entre os alunos, seus professores universitários e os demais integrantes do movimento da aprendizagem.

Currículo, na perspectiva analítica proposta por este Simpósio, é então não só o documento preestabelecido, a norma prescritiva dos conteúdos a serem estudados e das metodologias e/ou abordagens para o tratamento de tais conteúdos, como também o produto de um processo construído pelos seus praticantes.

Nesse sentido, este artigo debaterá alguns aspectos que revelam como os cursos de Letras da UEPG abordam a formação de professores de línguas em seus currículos, focando principalmente o papel dos estágios e das práticas nos processos formativos dos/as graduandos/as.

Na UEPG, temos três cursos de Licenciatura em Letras (Espanhol, Francês e Inglês), todos em dupla habilitação. O curso de Letras Espanhol/Português surge no ano de 1994. Sendo uma dupla habilitação, os/as graduandos/as devem cumprir o estágio de língua materna (LM) no $3^{\circ}$ ano e o de língua estrangeira (LE) no $4^{\circ}$ ano. No projeto institucional, o professor responsável pelo estágio nas licenciaturas tem uma carga horária que favorece o acompanhamento de estagiários/as em campo, ou seja, é possível elaborar um cronograma de trabalho para os/as graduandos/as de forma a acompanhá-los/as nos momentos de inserção nas escolas, inclusive nas regências. As práticas articuladoras, por sua vez, ocorrem do $1^{\circ}$ ao $4^{\mathrm{o}}$ ano dos respectivos cursos.

No período de 2012 a 2014, passamos por uma reestruturação da proposta curricular. Em 2015, temos o início da implantação dessa nova proposta e, nela, houve consideráveis mudanças nas disciplinas de Estágios e Práticas.

Assim, este trabalho objetiva fazer análise documental do PPC. Além disso, confrontar o PPC escrito com o vivido de forma a evidenciar os caminhos já percorridos nesta implantação curricular para contemplar a proposta e as estratégias que ainda precisam ser desenvolvidas para que o currículo se efetive de maneira mais coerente e efetiva.

\section{Discutindo o PPC Letras da UEPG: As Práticas Articuladoras e os estágios}

As palavras-chave de nosso PPC Letras da UEPG são leitura, escrita, oralidade e ensino. Sendo que a pesquisa é um dos eixos norteadores do curso. O perfil almejado para licenciados/as é a atitude de pesquisa, espírito de iniciativa e autonomia da ação pedagógica (atuar como professor-pesquisador).

(...) o perfil almejado para o licenciado em Letras Português/língua adicional/estrangeira e respectivas literaturas baseia-se, fundamentalmente, em três aspectos: atitude de pesquisa, espírito de iniciativa e autonomia da ação pedagógica, requisitos essenciais para compreender que sua formação profissional é 
um processo contínuo, autônomo e permanente, condições necessárias para atuar como professor-pesquisador. Estágios e Práticas são disciplinas fundamentais na formação docente de graduandos/as dos cursos de Licenciatura em Letras, assim, estas disciplinas necessitam dialogar e se complementar almejando contribuir com a construção de conhecimentos pedagógicos e vivências pedagógicas significativos para uma profissionalização docente de qualidade. (PPC - Letras Espanhol/Português UEPG, 2015, p. 13)

As Práticas Articuladoras se propõem contribuir com o perfil traçado para nossos/as licenciandos/as reconhecendo que o conhecimento deve recorrer à prática e ao grupo de problemas e questionamentos que nascem no diálogo com as situações conflituosas do cotidiano. A prática, nesse sentido, se configura mais como um processo de investigação do que um contexto de aplicação. Um processo de investigação na ação, mediante o qual o acadêmico submerge no mundo complexo do universo sócio-histórico e cultural no qual está inserida a escola para compreendê-la de forma crítica e vital, com o intuito de propor e experimentar alternativas, participando na reconstrução permanente da realidade escolar, em um processo contínuo, autônomo e permanente,

As Práticas precisam ser cumpridas em, pelo menos, 400 horas. Na proposta do PPC Letras da UEPG, essas práticas ocorrerão ao longo de todo o processo formativo nas licenciaturas ( $1^{\circ}$ ano - LM; $2^{\circ}$ ano - LE; $3^{\circ}$ e $4^{\circ}$ anos - em forma de Projetos), sendo que estarão, intrinsicamente, conectadas ao estágio e às atividades de trabalho conclusão de curso (TCC), colaborando para a formação da identidade docente como educador e, em ambos os casos, há necessidade de supervisão do momento formativo. No $1^{\circ}$ e $2^{\circ}$ ano, as Práticas Articuladoras serão cursadas no formato de disciplina, com 68 horas anuais cada. No $1^{\circ}$ ano, temos a seguinte ementa: "Estudo de documentos oficiais orientadores da prática pedagógica e os conceitos que os sustentam; reflexão sobre o ensino de língua portuguesa e literaturas de língua portuguesa no Ensino Básico (Fundamental e Médio) por meio da prática mediada da leitura e da escrita". No $2^{\circ}$ ano, a ementa se concentra em aspectos relacionados às Línguas Estrangeiras que compõem a dupla habilitação; neste caso, coloco a descrição para o PPC de Letras Espanhol/Português:

Práticas reflexivas sobre as teorias linguísticas e educacionais referentes ao processo de ensino/aprendizagem de Língua Espanhola e suas literaturas, englobando o estudo de questões relacionadas ao planejamento didático, processos avaliativos, análise, elaboração e aplicação de materiais didático pedagógicos no cotidiano escolar em consonância com as políticas educacionais vigentes. (PPC - Letras Espanhol/Português UEPG, 2015, p. 80)

As Práticas III e IV, como mencionado, foram propostas para serem realizadas em forma de projeto, cada uma com 136 horas anuais. A ementa de ambas as disciplinas ficou assim "Atividades integradas para a formação do professor: ensino, pesquisa e extensão".

Esta perspectiva das práticas está relacionada com a flexibilização curricular tratada no Plano de Desenvolvimento Institucional (PDI) da instituição e também nas Diretrizes Curriculares Nacionais dos Cursos de Letras (2001). O PDI da UEPG (2013, p. 76) preconiza que "o princípio da flexibilização curricular implica na possibilidade do acadêmico construir percursos formativos diferenciados, mais próximos de suas características e interesses".

Além disso, a proposta se pauta no princípio de que os trabalhos desenvolvidos pelos graduandos/as serão direcionados para gerar impacto na escola, vinculando-se às problemáticas elaboradas por eles/as ao final do segundo ano do Curso e aos compromissos com o pré-projeto do TCC, o qual terá início no $3^{\circ}$ ano do Curso, mesmo que posteriormente esse projeto passe por adequação.

No que se refere aos estágios, especificamente, fica estabelecido que as disciplinas de Estágio em LM e LE devem ser realocadas no Departamento de Estudos da Linguagem 
(DEEL), o qual se formou com a união do DELIN, Departamento de Letras Vernáculas (DELET) e Estágios em Línguas (DEMET). Essa união departamental teve como um de seus objetivos:

(...) uma aproximação e uma construção conjunta de conhecimento e projetos dos professores de línguas e literaturas com os professores da área de estágio. Essa aproximação, tão fundamental para a formação de um graduado na perspectiva do professor pesquisador em que ensino, pesquisa e extensão estabelecem um diálogo, não é privilegiada com a disciplina de estágio em departamento distante do curso de Letras. (PPC - Letras Espanhol/Português UEPG, 2015, p. 78)

A perspectiva de formação docente é a do professor pesquisador, por isso o conceito de professor reflexivo-crítico (PIMENTA e GHEDIN, 2005) é tão fundamental para as discussões do Curso. Ainda nesta mesma direção, entendemos que não se pode desvincular a teoria da prática e o conceito de práxis (VÁZQUEZ, 1977) ganha importância. Dessa forma, a relação dos Estágios com as Práticas Articuladoras tende a se tornar intrínseca.

Além disso, o projeto de estágio da UEPG nos permite acompanhar os/as graduandos/as em campo de estágio e, mais especificamente, no momento das regências. Este acompanhamento possibilita uma problematização da relação teoria e prática mais intensamente ao longo de todo o curso.

No PPC, estão listadas as seguintes atividades de estágio para a área de LM:

- $\quad$ estudo do meio educacional;

- $\quad$ análise e reflexão das concepções metodológicas e implicações legais vigentes no ensino de Língua Portuguesa e Literatura;

- $\quad$ observações participativas em turmas de $3^{\circ}$ e $4^{\circ}$ ciclos do ensino fundamental e médio;

- $\quad$ elaboração de projetos de ensino (leitura, produção de textos, análise linguística e literatura);

- $\quad$ planejamento de ações docentes;

- $\quad$ direções de classe (mini-cursos, oficinas literárias e/ou regências em

turmas regulares de ensino fundamental e médio);

- $\quad$ reflexões teórico-práticas sobre o ensino de Língua Portuguesa e

Literatura, no Ensino Fundamental e Médio, na perspectiva do/a professor/a pesquisador/a;

- $\quad$ seminários finais interdisciplinares (língua materna e língua

estrangeira) de análise de todas as atividades de estágio realizadas na $3^{\mathrm{a}}$ e $4^{\mathrm{a}}$ séries do Curso de Letras.

(PPC - Letras Espanhol/Português UEPG, 2015, p. 67-68)

Para a área de LE, temos a seguinte lista de atividades:

- observação participativa em turmas de $3^{\circ}$ e $4^{\circ}$ ciclos do ensino fundamental e médio;

- $\quad$ estudo do meio (escola estagiada);

- $\quad$ elaboração de projeto;

- $\quad$ elaboração de planos de aula;

- $\quad$ produção didático-pedagógica e sua implementação;

- $\quad$ seminários de apresentação dos projetos com alunos, professores da

rede estadual das escolas estagiadas e supervisor de estágio;

- $\quad$ regências;

- $\quad$ orientações e participações em eventos.

(PPC - Letras Espanhol/Português UEPG, 2015, p. 68) 


\section{Um exemplo: $O$ estágio de espanhol ${ }^{1}$}

De forma muito simplificada, a organização da disciplina de Estágio em Língua Espanhola na UEPG ocorre em encontros semanais, por meio da organização do campo de estágio, pela elaboração de sequências didáticas (SDs) utilizando gêneros textuais, pelas intervenções pontuais (clínica da atividade) e, mais tarde, por elaboração de artigo discutindo a relação teórico/prática nos processos desenvolvidos ao longo da disciplina no primeiro semestre e, por fim, pelas regências e feedback do que foi trabalhado nas regências. A seguir, tratarei de como ocorre cada uma dessas etapas.

Nossos encontros semanais são as aulas na universidade. Além de aproveitar este tempo ao máximo para os estudos teóricos, também nos dedicamos à organização do campo de estágio ao longo de toda a disciplina. Logo na primeira aula, os alunos ${ }^{2}$ receberam o cronograma de atividades para o primeiro semestre. Para o segundo semestre, no entanto, este cronograma foi pensado conjuntamente com alunos a partir das necessidades que apontaram como mais urgentes em sua formação, principalmente baseando-se nas vivências da realidade escolar que ocorreu no primeiro semestre.

No primeiro semestre, portanto, o cronograma de aulas foi organizado da seguinte maneira $^{3}$ : No primeiro mês, houve uma preocupação em discutir o contexto de ensino de espanhol no Brasil e o significado de ser professor de E/LE em tal contexto; ou seja, nos focamos mais nos aspectos das políticas linguísticas para a área de LEs. No segundo mês, nos voltamos para a compreensão da importância do estágio no processo formativo nas licenciaturas, o conceito de professor reflexivo-crítico em sua relação com o estágio e estudamos a teoria dos gêneros textuais, juntamente com o conceito de sequência didática (SD). No terceiro mês, continuamos as discussões sobre a teoria dos gêneros textuais, tratamos da organização do plano de aula e foram apresentadas as primeiras versões das SDs. No quarto mês, seguimos com as apresentações das primeiras versões das SDs e houve a discussão dos vídeos gravados nas observações participativas e elaboração de roteiro de avaliação das regências a partir das discussões sobre esses vídeos.

No segundo semestre, tivemos a seguinte proposição: No primeiro mês, finalizamos a discussão do ensino de gramática em uma perspectiva indutiva, retomamos o conceito de professor reflexivo-crítico e estagiários/as debateram como tal conceito influenciou sua prática ao longo do primeiro semestre. No segundo mês, estudamos o trabalho com a expressão oral e abordamos a avaliação relacionada à produção escrita do gênero textual estudado na SD. No terceiro mês, os/as estagiários/as apresentaram banners com o objetivo de relacionar o conceito de professor reflexivo-crítico com atividade/s desenvolvida/s na disciplina. No quarto mês, lemos o artigo "De que modo introduzir a literatura nas aulas de língua espanhola no Ensino Médio?” de Ligia Paula Couto e Gabriela B. M. F. B. de Souza (2016) e discutimos a importância de se trabalhar a literatura nas aulas de E/LE. Também debatemos as Leis $10.639 / 2003^{4}$ e $11.645 / 2008^{5}$ no ensino de E/LE, principalmente

\footnotetext{
${ }^{1}$ Trabalho com a disciplina de Estágio Curricular Supervisionado de Língua Espanhola desde 2008, por isso faço uma descrição mais pormenorizada de sua organização e não das disciplinas de Prática Articuladora.

${ }^{2}$ No ano de 2016, trabalhei com a turma do vespertino, a qual era constituída por 9 alunas e 1 aluno.

${ }^{3}$ No primeiro semestre, os textos de leitura que foram referência para as discussões propostas foram: "O ensino de espanhol no Brasil” de Villalba (2013). "Estágio e docência: diferentes concepções" de Pimenta e Lima (2005/2006). "Sequências didáticas para o oral e a escrita: apresentação de um procedimento" de Dolz, Noverraz y Scheneuwly (2004). "Professor reflexivo: da alienação da técnica à autonomia da crítica" de Ghedin (2005). "Diretrizes Curriculares de Línguas Estrangeiras Modernas do Paraná" (2008).
}

\footnotetext{
${ }^{4}$ A Lei 10.639/2003 estabelece o seguinte: Art. 1ํ A Lei no 9.394, de 20 de dezembro de 1996, passa a vigorar acrescida dos seguintes arts. 26-A, 79-A e 79-B:

"Art. 26-A. Nos estabelecimentos de ensino fundamental e médio, oficiais e particulares, torna-se obrigatório o ensino sobre História e Cultura Afro-Brasileira.
} 
retomando ações do projeto PIBID Espanhol/Português da UEPG ${ }^{6}$ que aborda essas questões. Por fim, no quinto mês, fizemos o fechamento da disciplina, com feedback individual e coletivo das atividades apresentadas pelos/as estagiários/as ao longo do curso.

O campo de estágio sempre é organizado em parceria com professores que compreendem e querem cooperar com a proposta da disciplina, que entendem a importância da práxis (PIMENTA e LIMA, 2008) e aceitam fundamentar suas práticas na teoria dos gêneros textuais e na interculturalidade. Nesta perspectiva de colaboração do professor em formação inicial com o professor em formação continuada, concordamos com Aroeira (2014, p. 136) para quem o estágio é um momento de reflexão da prática docente tanto para os/as estagiários/as quanto para os/as professores/as orientadores/as e professores/as da escola, de modo que todos/as os/as envolvidos/as no processo tenham a oportunidade de "ressignificar suas identidades profissionais, que estão em constante construção, a partir das novas demandas que a sociedade coloca para ação docente na escola".

Para a ressignificação, o/a graduando/a será o/a interlocutor/a entre as vivências da escola e as teorias e conhecimentos abordados na universidade, o que possibilitará construção de novos saberes a respeito do ensino de espanhol no contexto atual brasileiro. Assim, estamos de acordo com Aroeira (2014, p. 136-137):

$\mathrm{O}$ aluno em formação inicial, ao vivenciar o processo de estágio supervisionado no âmbito das instituições escolares, pode ser um interlocutor no momento de pesquisar as vivências do professor da escola e estudar as relações estabelecidas no encontro/confronto pelos professores da universidade. Diante disso, as trocas entre os professores da escola e da universidade poderão subsidiar a construção de novos saberes, além de aproximar os futuros professores das atividades profissionais, visto que, nessa perspectiva, o estágio preocupa-se não só em observar, mas também em problematizar, investigar e analisar a realidade escolar por meio de um processo mediado pela reflexão dos atores envolvidos.

Em 2016, o campo de estágio foi desenvolvido em três escolas, com três professores diferentes; um dos professores atuava no CELEM e em uma escola com turmas de espanhol no EF II; as outras duas professoras atuavam em uma escola com turmas de espanhol no EM. Dessa forma, conseguimos abarcar todas as possibilidades de organização do ensino de espanhol na escola pública: CELEM, EF e EM.

§ 1ㅇ O conteúdo programático a que se refere o caput deste artigo incluirá o estudo da História da África e dos Africanos, a luta dos negros no Brasil, a cultura negra brasileira e o negro na formação da sociedade nacional, resgatando a contribuição do povo negro nas áreas social, econômica e política pertinentes à História do Brasil. $\S 2$ o Os conteúdos referentes à História e Cultura Afro-Brasileira serão ministrados no âmbito de todo o currículo escolar, em especial nas áreas de Educação Artística e de Literatura e História Brasileiras.

"Art. 79-B. O calendário escolar incluirá o dia 20 de novembro como 'Dia Nacional da Consciência Negra'."

5 a Lei 11.645/2008 amplia o estabelecido na Lei 10.639/2003, com o intuito de incluir as culturas de origem indígena:

“Art. 26-A. Nos estabelecimentos de ensino fundamental e de ensino médio, públicos e privados, torna-se obrigatório o estudo da história e cultura afro-brasileira e indígena.

$\S 1$ o O conteúdo programático a que se refere este artigo incluirá diversos aspectos da história e da cultura que caracterizam a formação da população brasileira, a partir desses dois grupos étnicos, tais como o estudo da história da África e dos africanos, a luta dos negros e dos povos indígenas no Brasil, a cultura negra e indígena brasileira e o negro e o índio na formação da sociedade nacional, resgatando as suas contribuições nas áreas social, econômica e política, pertinentes à história do Brasil.

$\S$ 2o Os conteúdos referentes à história e cultura afro-brasileira e dos povos indígenas brasileiros serão ministrados no âmbito de todo o currículo escolar, em especial nas áreas de educação artística e de literatura e história brasileiras."

${ }^{6} \mathrm{O}$ projeto PIBID Espanhol/Português da UEPG teve sua primeira em 2011 e, desde 2014, está em sua segunda edição. 
Para inserir os/as graduandos/as em campo de estágio, além de considerar a disponibilidade para acompanhar as aulas do/a professor/a, também discutimos suas preferências com relação ao nível de ensino a trabalhar, sempre explicando que não há nível mais fácil ou mais difícil, as dificuldades e os obstáculos serão diferenciados para cada contexto.

Em seguida, estabelecemos um dia para visitar a escola e conversar com o/a professor/a das turmas. Neste primeiro encontro, discutimos primordialmente as expectativas do/a professor/a com relação ao/à estagiário/a e a postura do/a estagiário/a numa observação participativa e também elegemos a turma correspondente a cada estagiário/a para a realização das regências. A partir deste primeiro encontro, foi organizado um calendário para o cumprimento de trinta e duas aulas de observação participativa. Durante este período de observação, os/as graduandos/as precisaram estabelecer, juntamente com o/a professor/a, alguns momentos de inserção em que o/a graduando/a teria que fazer filmagem atuando em sua provável turma de regência para, em encontro presencial na universidade, discutir uma dessas filmagens com professora e colegas de curso.

É importante explicar que as trinta e duas aulas de observação participativa foram cumpridas durante $\mathrm{o} 1^{\mathrm{o}}$ semestre. Cada estagiário/a foi um dia por semana à escola e acompanhou o/a professor/a em atuação neste dia; sendo que o dia selecionado correspondeu ao dia em que a provável turma de regência desse/a estagiário/a tinha aula. Em média, os/as estagiários/as levaram dois meses para finalizar as observações, de abril a maio.

As observações, além do caráter participativo e de vivência escolar pelo/a graduando/a, tiveram importância significativa na organização das SDs também, uma vez que a proposta da disciplina sempre foi aliar os estudos teóricos à prática. Enquanto discutíamos a teoria dos gêneros textuais em sala, juntamente com a proposta de SD organizada por Dolz, Noverraz e Scheneuwly (2004), os/as graduandos/as tinham que elaborar seu projeto de SD respeitando os conteúdos sugeridos pelo/a professor $/ \mathrm{a}^{7}$ para sua provável turma de regência e temáticas adequadas à realidade dos/as alunos/as. Além disso, durante o período de observação, nossos encontros na universidade se iniciavam com o debate a respeito do que haviam vivenciado nas escolas aquela semana, sempre buscando problematizar a questão da relação teoria/prática e a possibilidade de construir um ensino de E/LE de qualidade nos contextos em que nos inserimos. A SDs, como tinham que seguir o esquema sugerido por Dolz, Noverraz e Scheneuwly (2004), foram organizadas com apresentação da situação, produção inicial, os módulos e a produção final, sendo que foram totalmente escritas em língua espanhola.

Ao término das SDs, os/as estagiários/as tiveram que elaborar artigos. No artigo, foram orientados/as para desenvolver a escrita totalmente em espanhol, com fundamentação teórico/prática. Isso significa que toda a discussão da prática deveria apresentar fundamentação teórica e toda teoria discutida deveria trazer um aspecto prático. $\mathrm{O}$ artigo, ainda, precisaria apresentar três partes: Introdução, desenvolvimento teórico-prático e conclusão.

$\mathrm{Na}$ introdução, ficou estabelecido que seria importante que o/a estagiário/a descrevesse seu posicionamento em relação ao ensino de E/LE (suas experiências, sua

\footnotetext{
${ }^{7}$ Gostaria de ressaltar que já temos professores/as que, conforme estabelecido na DCE-PR (2008), postulam determinados gêneros textuais como conteúdo para as regências dos/as estagiários/as. No entanto, ainda há professores/as que indicam algum vocabulário em específico; e não é raro o/a professor/a sugerir um aspecto gramatical. A seleção de conteúdos pelos/as professores/as também foi motivo de discussão em nossas aulas na universidade, principalmente para nos questionar por que nos limitamos a uma perspectiva de ensino de E/LE tão estrutural, ou ainda, tradicional, quando há documentos oficiais, discussões teóricas que defendem outros caminhos e, inclusive, práticas já divulgadas sobre este ensino que podem se realizar de forma diferenciada? Nesse contexto, o processo do estágio pode resultar em uma formação continuada para os/as professores/as da rede pública e em um debate a respeito dos processos de ensino/aprendizagem de E/LE na relação teoria/prática com esses/as professores/as.
} 
vontade em trabalhar com aulas de espanhol, seu perfil como estudante do curso de Letras Espanhol, etc.), o grupo de estudantes com o qual trabalhou nas regências, a escola e a proposta de trabalho do/a professor/a do grupo. Além disso, teria que explicar o tema e o gênero selecionados para sua SD.

No desenvolvimento teórico/prático, o/a estagiário/a teve que discutir a concepção de língua que fundamenta suas práticas, a perspectiva de ensino de espanhol considerando a concepção de língua e o papel do professor e do aluno nesta perspectiva de ensino. Além disso, ele/a precisou explicar o significado dos termos "gênero textual" e "sequência didática" e a relação desses termos com os processos de ensino/aprendizagem de espanhol. Por fim, nesta parte do artigo, o/a estagiário/a explicitou as características do gênero selecionado para ser trabalhado em sua SD e selecionou cinco atividades propostas na SD para apresentação de seu objetivo de ensino/aprendizagem e sua relação com as teorias apresentadas.

A conclusão foi o momento em que o/a estagiário/a teve para analisar o caminho de construção de sua SD e seu aprendizado em relação à teoria e à prática para o ensino de E/LE no contexto específico em que atuou. Ademais, foi pedido a ele/a para a analisar a importância deste processo de formação referente à teoria do professor crítico-reflexivo.

Por fim, as observações ganharam ainda mais significado quando os/as estagiários/as tiveram que iniciar o trabalho de breves inserções com filmagens. Essas filmagens foram baseadas na clínica da atividade desenvolvida pelo pesquisador francês Yves Clot. De acordo com seus estudos (2006, p. 127), a clínica da atividade seria a "análise psicológica do trabalho", feita por um sujeito ou grupo em determinado contexto. Essa análise do trabalho significa que o sujeito ou grupo se referirão "àquilo que os homens fazem com as provações pelas quais passam e das soluções que eles encontram, ou não encontram, a fim de enfrentalas" (CLOT, 2006, p. 127).

Para nós, a clínica da atividade funcionou da seguinte maneira: Cada estagiário/a filmou breves inserções nas aulas de E/LE em sua possível turma de regência (foi sugerido que eles/as fizessem pelo menos três inserções) e escolheu uma dessas filmagens para apresentar e discutir em aula na universidade. Esta discussão teve o intuito de debater, mais uma vez, a relação teoria/prática e construir um roteiro de avaliação das regências pela professora orientadora. A avaliação das regências, portanto, foi elaborada a partir da interação de estagiários/as e professora orientadora a partir da análise das filmagens das intervenções nas observações participativas.

Após todo esse processo, chegamos ao momento das regências. As regências totalizaram oito aulas. No contexto do CELEM, essas oito aulas representaram duas semanas de trabalho e, na escola regular (EF II e EM), um mês de trabalho. Todos/as os/as estagiários/as desenvolveram as regências no $3^{\circ}$ bimestre, de agosto a setembro e foram acompanhados/as por mim. Durante o acompanhamento dessas regências (em média, assisti cinco aulas de cada estagiário/a), preenchi o roteiro de avaliação elaborado durante nossas discussões sobre as filmagens e também fiz apontamentos. Todo este material foi discutido com os/as estagiários/as nos meses de novembro e dezembro, em dinâmicas realizadas em encontros coletivos e individuais. Nos encontros coletivos, o debate ocorreu em torno dos pontos positivos identificados na maioria das regências e dos que ainda precisavam ser revistos e repensados de maneira geral pelo grupo. Nos encontros individuais, o objetivo foi tratar das especificidades da atuação de cada estagiário/a.

\section{PPC: Caminhos percorridos}

Os caminhos percorridos, até agora, se revelam a partir da compreensão do PPC no que se refere às disciplinas de Estágios e Práticas por parte dos docentes do curso. Nesse sentido, ocorreu no ano de 2016 mais especificamente, a conscientização da necessidade de trabalho em conjunto por parte dos professores. 
No início do ano letivo, houve reuniões com os docentes das disciplinas de Didática, Estágios e Práticas para discutir suas proximidades e eleger temas que pudessem ser discutidos em todas elas em eventos conjuntos. A ideia inicial é que haveria um encontro conjunto por bimestre, sendo que os temas escolhidos foram: 1) Identidade docente (o que estou fazendo aqui/ o que fiz aqui); 2) Professor pesquisador, professor reflexivo-crítico e autonomia; c) Ensino de Língua e Literatura; d) Concepções de Língua e Linguagem.

No entanto, como houve um excesso de atividades e um período de greve ao longo do ano letivo, sintetizamos nossos encontros em uma ação: um evento entre todas as séries dos cursos para abordar a teoria do professor reflexivo-crítico em relação às disciplinas referidas. Neste evento, os/as graduandos/as tiveram que fazer e debater as mesmas leituras (nota) e organizar exposição de suas ideias. E, a partir dessas leituras e debates, expor suas discussões em formato de banner para suas respectivas turmas (individualmente, em pares ou grupos, conforme orientação de professores/as das disciplinas).

Para o evento em conjunto, as turmas de $1^{\circ}$ ano tiveram que expor suas discussões em formato de banner e as turmas de $2^{\circ}$ a $4^{\circ}$ anos tiveram que apresentar banner em sala de aula $\mathrm{e}$ escolher um representante da turma para levar a discussão ao momento do evento. Esse representante ficou com a tarefa de apresentar seu trabalho no evento e problematiza-lo por meio de perguntas e debate com professor mediador das apresentações e com o público participante (graduandos/as de $1^{\circ}$ a $4^{\circ}$ ano e professores/as dos Cursos de Letras).

Além disso, se buscou uma compreensão do PPC no que se refere à disciplina de Prática (principalmente a III e IV) em sua relação com a flexibilização por parte da UEPG Pró Reitoria de Graduação (PROGRAD), Conselho de Ensino, Pesquisa e Extensão (CEPE), etc. O NDE Letras teve que atuar fortemente no sentido de esclarecer para a instituição a proposta dessas Práticas Articuladoras e encaminhar ofícios à PROGRAD e outros órgãos pedindo uma organização burocrática para atender a proposta, pois o sistema institucional não estava completamente adequado para a implantação das Práticas no formato de Projetos.

Tanto para o trabalho com professores/as e graduandos/as quanto com órgãos da UEPG (PROGRAD, CEPE, etc.), o NDE Letras foi o eixo que congregou e organizou as ações para que a proposta do PPC se efetivasse. A articulação do NDE Letras com o colegiado, demais professores/as do curso e graduandos/as tem sido essencial para que as Práticas Articuladoras e os Estágios se concretizem da maneira mais próxima possível do que foi idealizado no PPC.

\section{PPC: Caminhos a percorrer}

Apesar de todo o trajeto já traçado e dos esforços do NDE Letras, ainda precisamos caminhar para esclarecer nossas ações. No que se refere aos estágios, é importante: a) organizar uma linha mais coesa de trabalho; b) tornar o trabalho dos estágios mais claro para os/as professores/as do curso; c) valorizar os estágios ao longo de todo o curso, tornando-o um eixo estruturador das ações pedagógicas no geral. No tocante à Práticas, é necessário: a) organizar uma linha mais coesa de trabalho; b) tornar o trabalho das práticas mais claro para os/as professores/as do curso; c) implantar as Práticas III e IV em forma de projetos da maneira estruturada no PPC. Por fim, sobre os Estágios e as Práticas (III e IV): tornar essas disciplinas campo de conhecimento para auxiliar na construção do TCC.

\section{Referências}

ALVES, Nilda. Criar currículo no cotidiano. São Paulo: Ed. Cortez, 2002.

AROEIRA, Kalline Pereira. Estágio supervisionado e possibilidades para uma formação com vínculos colaborativos entre a universidade e a escola. In: ALMEIDA, Maria Isabel de; 
PIMENTA, Selma Garrido (Orgs). Estágios Supervisionados na Formação Docente. São Paulo: Editora Cortez, 2014, p. 113-151.

BRASIL. Diretrizes Curriculares Nacionais dos Cursos de Letras. MEC, 2005. Disponível em: < http://portal.mec.gov.br/cne/arquivos/pdf/CES0492.pdf>. Acesso em: 14 dez. 2016.

CLOT, Yves. A função psicológica do trabalho. Petrópolis, RJ: Editora Vozes, 2006.

COUTO, Ligia Paula; SOUZA, Gabriela Beatriz Moura Ferro Bandeira de. De que modo introduzir a literatura nas aulas de língua espanhola no Ensino Médio? In: COUTO, Ligia Paula. Didática da língua espanhola no ensino médio. São Paulo: Editora Cortez, 2016.

DOLZ, Joaquim; NOVERRAZ, Michèle; SCHNEUWLY, Bernard. Sequências didáticas para o oral e a escrita: apresentação de um procedimento. In: SCHNEUWLY, Bernard; DOLZ, Joaquim (Orgs.). Gêneros orais e escritos na escola. Campinas, SP: Mercado de Letras, 2004, p. 81-108.

MOREIRA, Antonio Flavio; SILVA, Tomaz Tadeu. Currículo, cultura e sociedade. São Paulo: Ed. Cortez, 1994.

PARANÁ. Diretrizes Curriculares da Educação Básica: língua estrangeira Moderna. SEED: Paraná, 2008.

PIMENTA, Selma Garrido; GHEDIN, Evandro (Orgs.). Professor Reflexivo no Brasil: gênese e crítica de um conceito. São Paulo: Editora Cortez, 2005, p. 17-52.

PIMENTA, Selma Garrido; LIMA, Maria Socorro Lucena. Estágio e docência. São Paulo: Cortez, 2008.

UEPG. PPC Letras Português/Espanhol. Disponível em: <http://www.uepg.br/cepe/atosoficiais/2015/014.pdf>. Acesso em: 24 out. 2016.

Plano de Desenvolvimento Institucional. 2013. Disponível em: < http://www.pitangui.uepg.br/secrei/externas_con/resolucoes/RESUNIV\%202013/Resuniv001. pdf>. Acesso em: 14 dez. 2016.

VÁZQUEZ, Adolfo Sánchez. Filosofia da práxis. Rio de Janeiro: Paz e Terra, 1977. $2^{\mathrm{a}}$ ed.

VILLALBA, Terumi Koto Bonnet. O ensino de español no Brasil: Revisitando o tema da política linguística. In: ZORZO-VELOSO, Valdirene F.; FERREIRA, Cláudia Cristina; ORTIGOZA, Arelis Felipe (Orgs.). El español en línea de mira: enlaces lingüísticos, literarios y metodológicos. Londrina: UEL, 2013. 